\title{
化学増幅法による都市污染大気中の過酸化ラジカルの測定
}

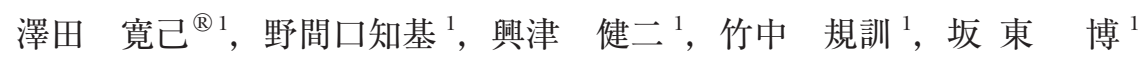

\section{Measurement of atmospheric peroxy radicals in the polluted-urban air using a chemical amplification}

\author{
Hiromi SAWAdA $^{1}$, Tomoki Nomaguchi ${ }^{1}$, Kenji OKITSU ${ }^{1}$, \\ Norimichi TAKENAKA ${ }^{1}$ and Hiroshi BANDOW ${ }^{1}$
}

\footnotetext{
${ }^{1}$ Department of Applied Materials Science, Graduate School of Engeneering, Osaka Prefecture University, 1 - 1 , Gakuen-cho, Sakai-shi, Osaka 599 - 8531
}

(Received 7 May 2004, Accepted 19 August 2004)

\begin{abstract}
In September 2001, January 2002 and December 2003, we measured peroxy radicals $\left(\mathrm{RO}_{2}\right)$ in urban polluted air using the Peroxy Radical Chemical Amplification (PERCA) method. Since the observation site in 2003 was much affected by automobile exhaust, during the observatiion the average $\mathrm{NO}_{\mathrm{x}}$ concentration exceeded 90 pptv. In this observation, the daytime $\mathrm{RO}_{2}$ cancentration was similar to that at other observation sites, and in the reported literature. However, in 2003 measurement, the nighttime $\mathrm{RO}_{2}$ concentration was found to be below the detection limit (3.5 pptv) most of the time. This result was different from the other two measurements. Though a difference was not seen in the $\mathrm{RO}_{2}$ concentration in the observations of 2001 and 2002, the average $\mathrm{O}_{3}$ concentration was very different. These results obtained in this study for urban polluted air can not be explained based on general knowledge about atmospheric chemistry, especially concerning the correlation between the $\mathrm{RO}_{2}$ and $\mathrm{O}_{3}$ concentrations.
\end{abstract}

Keywords : peroxy radicals; ozone; the polluted-urban air; PERCA; atmospheric chemistry.

\section{1 緒 言}

大気中に極微量に存在する $\mathrm{OH}$ ラジカルは大気中のほ とんどの微量成分の動態にかかわる活性種で，例えば，大 気中での非メタン炭化水素類など一次污染物質の寿命や, オゾンなど二次污染物質の生成に影響を与える. $\mathrm{HO}_{2}$ ラ ジカルは污染大気中ではNOと, 清浄大気中においては オゾンと反応することで $\mathrm{OH}$ を生成する，すなわち $\mathrm{OH}$ のリザーバとしてはたらく ${ }^{1) 2}$. 有機過酸化ラジカル $\left(\mathrm{RO}_{2}\right)$ は大気中での炭化水素類の酸化過程の中間体として存在す ることと，化学的に $\mathrm{HO}_{2}$ ラジカルとよく似た性質を示す ことから，上記の $\mathrm{HO}_{\mathrm{x}}\left(\mathrm{OH}+\mathrm{HO}_{2}\right)$ 同様，大気化学にお

\footnotetext{
*若手研究者の初論文特集

${ }^{1}$ 大阪府立大学大学院工学研究科機能物質科学分野：599-8531 大阪府堺市学園町 1 - 1
}

いて重要な物質である.よってこれらラジカルの環境中に 存在する濃度の測定は大気化学の反応系を知る上で重要で ある。

いくつか報告されている大気中 $\mathrm{OH}$ 及び過酸化ラジカ ル $\mathrm{RO}_{2}\left(\mathrm{HO}_{2}\right.$ を含む）の測定方法の一つとして化学増幅 法 (Peroxy Radical Chemical Amplification, PERCA) が ある. Cantrell らにより開発されたこの方法は, $\mathrm{RO}_{2}$ 類が 直接関与した連鎖反応において $\mathrm{NO}$ が $\mathrm{NO}_{2}$ に増幅変換さ れ，この反応により生じた $\mathrm{NO}_{2}$ を測定しラジカル濃度を 算出する方法である ${ }^{3) \sim 5)}$ 。この方法を用いた観測もいくつ か報告されている ${ }^{6) \sim 8)}$. このほかにも環境大気中のラジカ ル測定法としていくつか報告されており， $\mathrm{OH}$ や $\mathrm{HO}_{2}$ を 測定する方法としてレーザー誘起蛍光法（Laser Induced Fluorescence, LIF $)^{9) \sim 12)}$ や差分吸光光度法 (Differential Optical Absorption Spectroscopy, DOAS) ${ }^{13) 14)}$ があり, 多 
くの観測に利用されている．報告されている観測の多くは 炭化水素, $\mathrm{NO}_{\mathrm{x}}$ など污染物質の一次排出源の少ない地域 で行われている。この理由として，ラジカル種の反応性が 非常に大きく, 多くの物質と反応するために解析が困難で あることや，エアロゾルによるラジカルの消失など，観測 結果に及ぼす不確定要素が多いことが挙げられる.

本研究では, 比較的簡便で安価である PERCA 法を用い て大阪府堺市及び大阪府泉大津市における大気中の $\mathrm{RO}_{2}$ 濃度の測定を行った。また，得られた都市污染大気中での $\mathrm{RO}_{2}$ 濃度の日变動と他の污染物質, オゾンや $\mathrm{NO}_{\mathrm{x}}$ などと の関連について検討を行った。

\section{2 実験}

\section{$2 \cdot 1$ 化学増幅法}

化学増幅法において利用される一連の反応を以下に示 す.

$$
\begin{aligned}
& \mathrm{RO}_{2}+\mathrm{NO} \longrightarrow \mathrm{RO}+\mathrm{NO}_{2} \\
& \mathrm{RO}+\mathrm{O}_{2} \longrightarrow \mathrm{HO}_{2}+\mathrm{R}^{\prime} \mathrm{CHO} \\
& \mathrm{HO}_{2}+\mathrm{NO} \longrightarrow \mathrm{OH}+\mathrm{NO}_{2} \\
& \mathrm{OH}+\mathrm{CO} \longrightarrow \mathrm{H}+\mathrm{CO}_{2} \\
& \mathrm{H}+\mathrm{O}_{2}+\mathrm{M} \longrightarrow \mathrm{HO}_{2}+\mathrm{M}
\end{aligned}
$$

大気中に含まれる $\mathrm{RO}_{2}$ は, 添加され高濃度で存在する NO との反応により RO へ変換され（R-1），更に RO は空 気中に含まれる $\mathrm{O}_{2}$ との反応により $\mathrm{HO}_{2}$ へと変換される (R-2)．生じた $\mathrm{HO}_{2}$ は，大過剩に添加された $\mathrm{NO}$ 及び $\mathrm{CO}$ によって（R-3），(R-4），(R-5）式で表される反応を優先 的に繰り返すことで $\mathrm{NO}$ を $\mathrm{NO}_{2}$ へと変換させる。この増 幅変換の連鎖反応により生じた $\mathrm{NO}_{2}$ 濃度 $\left(\Delta \mathrm{NO}_{2}\right)$ から $\mathrm{RO}_{2}$ 濃度を求める。すなわち，連鎖反応回数を $N_{\mathrm{CL}}$ とす ると $\left[\Delta \mathrm{NO}_{2}\right]=\left[\mathrm{RO}_{2}\right] \times N_{\mathrm{CL}}$ で表される．また，この反応 の他に以下に示すような停止反応がある.

$$
\begin{aligned}
& \mathrm{RO}_{2}+\mathrm{NO}+\mathrm{M} \longrightarrow \mathrm{RONO}_{2}+\mathrm{M} \\
& \mathrm{RO}+\mathrm{NO}+\mathrm{M} \longrightarrow \mathrm{RONO}+\mathrm{M} \\
& \mathrm{OH}+\mathrm{NO}+\mathrm{M} \longrightarrow \mathrm{HONO}+\mathrm{M} \\
& \mathrm{RO}_{\mathrm{x}}+\text { wall } \longrightarrow \text { non-radical products } \\
& (\mathrm{x}=1 \text { or } 2)
\end{aligned}
$$

ここで wall とは実験装置内でラジカルが通過する経路 の壁面を指す。またこのほかに, $\mathrm{HO}_{2}+\mathrm{OH}, \mathrm{OH}+\mathrm{OH}$, $\mathrm{HO}_{2}+\mathrm{O}_{3}, \mathrm{OH}+\mathrm{NO}_{2}$ などの反応が存在するが, $\mathrm{OH}$ や $\mathrm{HO}_{2}, \mathrm{O}_{3}, \mathrm{NO}_{2}$ の濃度は, $\mathrm{NO}$ や $\mathrm{CO}$ に対して十分小さ いので，これらの反応は無視できる.

化学増幅法の校正には水蒸気・酸素同時光分解法を用い た $^{15)}$.これは水蒸気を含む空気に水銀ランプ $(\lambda=185$ $\mathrm{nm}$ ）を照射することで水分子を分解し， $\mathrm{OH}$ と水素原子 を生成し，水素原子は反応（R-5）によって $\mathrm{HO}_{2}$ を生成す るという方法である。このとき酸素原子も同時に分解し $\mathrm{O}_{3}$ を生成する。生成された $\mathrm{OH}$ は，校正ガスに $\mathrm{CO}$ を加 えることで $\mathrm{HO}_{2}$ に変換する $(\mathrm{R}-4,5)$. これらの反応から 下式が得られる。

ここで $\sigma_{\mathrm{H}_{2} \mathrm{O}}, \sigma_{\mathrm{O}_{2}}$ はそれぞれ水分子と酸素分子の 185 $\mathrm{nm}$ の

$$
\frac{\left[\mathrm{HO}_{2}\right]}{\left[\mathrm{O}_{2}\right]}=\frac{\sigma_{\mathrm{H}_{2} \mathrm{O}}}{\sigma_{\mathrm{O}_{2}}} \frac{\left[\mathrm{H}_{2} \mathrm{O}\right]}{\left[\mathrm{O}_{2}\right]}
$$

波長における吸光断面積を表しており，文献值を用いる. ガス中に含まれる水蒸気濃度及び $\mathrm{O}_{3}$ 濃度を測定すること により, この式から生成された $\mathrm{HO}_{2}$ 濃度が算出される. 発生させた $\mathrm{HO}_{2}$ 濃度が $100 \mathrm{pptv}$ 以下で連鎖反応回数 $N_{\mathrm{CL}}$ はほぼ一定となり，約 250 であった。

また，化学増幅法では，大気中の水蒸気の存在により増 幅率が減少することが報告されている ${ }^{16)}$. 本実験装置にお けるこの効果について, 校正ガスに水蒸気を更に加えるこ とで増幅率の水蒸気濃度による減衰を求めた。 その結果を 校正ガスに水蒸気を添加しないときの増幅率に対して，相 対湿度が約 $90 \% （ 298 \mathrm{~K} ）$ になると，連鎖反応回数は約 $35 \%$ に落ちる。実環境デー夕の解析時には，この湿度に よる影響を補正したものを用いた。

\section{$2 \cdot 2$ ルミノール化学発光法}

化学増幅反応により得られた $\mathrm{NO}_{2}$ の検出方法としてル ミノール化学発光法を用いた。この方法は, $\mathrm{NO}_{2}$ とルミ ノール溶液の気一液反応により生じる化学発光を測定する ものである ${ }^{17)}$. 一般に市販されている乾式の化学発光方式 窒素酸化物計とは異なり, ppmv レベルの高濃度 NO 共存 下においても ppbvレベルの $\mathrm{NO}_{2}$ の定量が可能である. 一方で，ルミノールが大気試料中に共存する他の酸化性物 質と反応し，化学発光を生じるという久点もある.

化学増幅法とルミノール化学発光法を組み合わせた実験 装置図を Fig. 1 に示す。増幅反応管 \{ o.d. $6.35 \phi \times 1480$ $\mathrm{mm}$ 四フッ化エチレン-パーフロロアルキルビニルエーテ ル共重合樹脂（PFA）管\}に導入された試料大気は NO （3 ppmv）及び CO（10\%）が添加される. 反応管内を通 った試料をその後テフロンフィルターに通し，ラジカルを 消失させ，増幅反応を停止させる，これにより，増幅反応 の反応時間は一定時間（本実験では 1.3 秒）に調節される. 反応セル内に導入された試料ガスに含まれる $\mathrm{NO}_{2}$ はセル 内にあるアルカリ性のルミノール水溶液と接触, 反応し, 化学発光を生じる. その発光の検出には光電子増倍管（浜 松フォトニクス，R268）を用いた。 


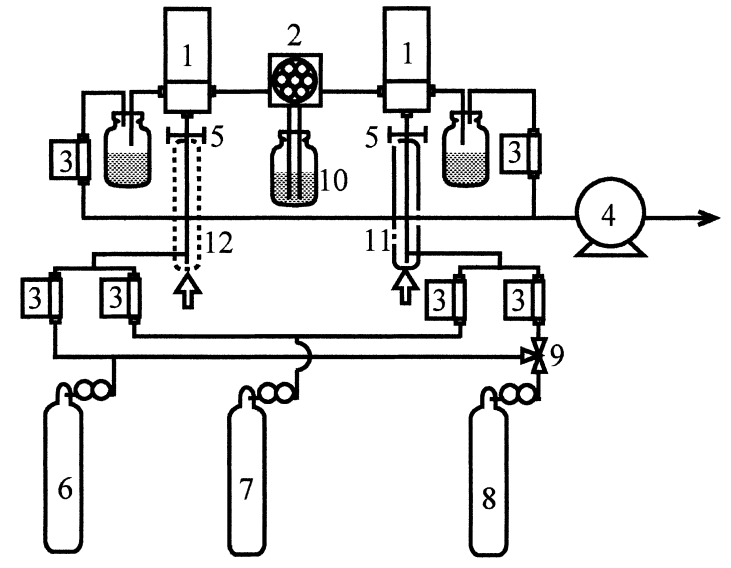

Fig. 1 Schematic drawing of a chemical amplifier instrument

1: luminol-chemiluminescence detector; 2 : peristartic pump ; 3: mass-flow controler ; 4: diaphragm pump; 5: Teflon filter; 6 : nitrogen; 7 : nitric oxide (100 ppmv)/nitrogen; 8: carbon monoxide; 9: 3-way-valve; 10: luminol solution; 11: PERCA reactor tube; 12 : reference tube, arrows: sample inlet

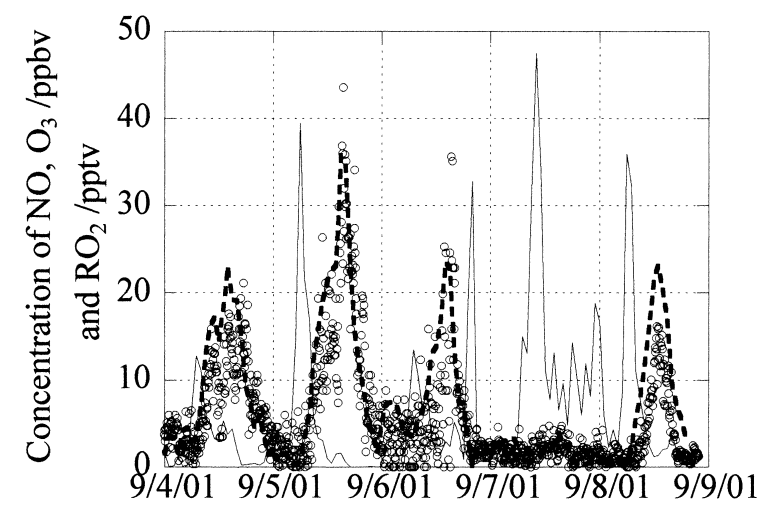

Fig. 2 Time profile of $\mathrm{RO}_{2}, \mathrm{NO}$ and $\mathrm{O}_{3}$ concentration at Osaka Prefecture Univ. (OPU), Sakai, in Sep. 2001

Solid and dashed lines show NO and ozone concentration, respectively. Open circles indicate $\mathrm{RO}_{2}$ concentration.

本法では $\mathrm{RO}_{2}$ 濃度を，連鎖反応により生成した $\mathrm{NO}_{2}$ の 濃度として測定している。しかしながら，大気中にも $\mathrm{NO}_{2}$ は存在し, 短い時間幅で濃度変動を示す。また, 実 大気に存在する $\mathrm{O}_{3}$ が増幅反応管内に導入されると高濃度 で添加された $\mathrm{NO}$ と反応し $\mathrm{NO}_{2}$ を生成する．このように， 実大気の測定においては大気中に存在する $\mathrm{NO}_{2}$ や $\mathrm{O}_{3}$ に より化学発光信号のベースラインが大きく影響を受ける. このため, 増幅反応により増加した $\mathrm{NO}_{2}$ 濃度上昇分 $\left(\Delta \mathrm{NO}_{2}\right)$ を判別することが困難となる．その対策として， $\mathrm{CO}$ を添加せず増幅反応が起こらない反応管を参照系とし

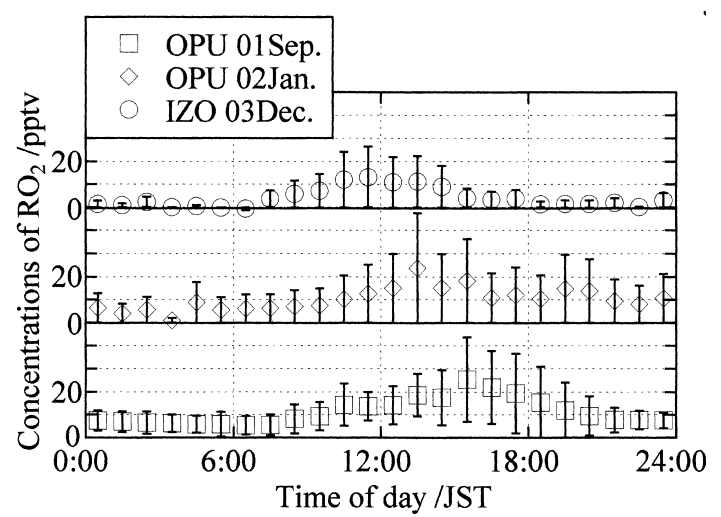

Fig. 3 Averaged diurnal variations of 1-hour average $\mathrm{RO}_{2}$ concentration for each measurement period

て設置している。これにより，大気中の $\mathrm{NO}_{2} や \mathrm{O}_{3}$ によ る干渉を相殺し， $\mathrm{RO}_{2}$ の連鎖反応で増幅した $\mathrm{NO}_{2}$ のみを 得ることができる。また，増幅反応系に招いても 3 分ご とに $\mathrm{CO}$ と $\mathrm{N}_{2}$ の導入を切り替え, 増幅反応が起こらない ようにすることで，参照系との同一性を随時確認しながら 測定を行うことができる.

\section{$2 \cdot 3$ 実大気観測}

2001 年 9 月と 2002 年 1 月に大阪府堺市の大阪府立大学 にて観測を行った。この敷地横には一次排出源と考えられ る国道が通っており，観測場所は道路から拈よそ $100 \mathrm{~m}$ 南である。このサイトでは $\mathrm{NO}_{\mathrm{x}}$, オゾンなどには一般的 な都市大気型の日変動が見られる。また，2003 年 12 月に 大阪府泉大津市においても観測を行った。観測場所は主要 幹線道路から約 $20 \mathrm{~m}$ のところにあり，ここは特に交通量 が多く, 高速道路もあるため, 自動車から排出された大気 污染物質がきわめて多い地域である。朝のラッシュアワー では $\mathrm{NO}_{\mathrm{x}}$ 濃度が $300 \mathrm{ppbv}$ 以上になることも過去に確認さ れている.

\section{3 結果と考察}

観測の一例として 2001 年 9 月における $\mathrm{NO}, \mathrm{O}_{3}$ 及び $\mathrm{RO}_{2}$ の濃度変化を Fig. 2 に示す．実線は $\mathrm{NO}$ を，点線は $\mathrm{O}_{3}$, Oは $\mathrm{RO}_{2}$ 濃度をそれぞれ表す。

Fig. 2 の結果を含む全 $\mathrm{RO}_{2}$ の観測結果を，1時間平均值 にした上で平均日変動として Fig. 3 に示す. 白抜きの四 角（ $\square ）$ が 2001 年 9 月の (OPU 0109), 白抜きの菱 $(\diamond)$ が 2002 年 1 月の大阪府立大学での測定結果 (OPU 0201) を，白抜きの丸（○）が 2003 年 12 月の大阪府泉大津市 での観測結果（IZO 0312）をそれぞれ示す.

すべての観測において共通しているのは, 日の出時間付 近から濃度の上昇が見られ（6:00〜 7:00 又は $7: 00 〜$ $8: 00), 13: 00 \sim 15: 00$ で最大となり, その後徐々に減 
Table 1 Mean and range of concentratioins of $\mathrm{CO}, \mathrm{NO}, \mathrm{NO}_{\mathrm{x}}$ and $\mathrm{O}_{3}$ in measurement period

\begin{tabular}{|c|c|c|c|c|c|c|}
\hline Site & Date & & $\mathrm{CO} / \mathrm{ppmv}$ & $\mathrm{NO} / \mathrm{ppbv}$ & $\mathrm{NO}_{\mathrm{x}} / \mathrm{ppbv}$ & $\mathrm{O}_{3} / \mathrm{ppbv}$ \\
\hline \multirow{8}{*}{ OPU } & \multirow{4}{*}{ Sep. 2001} & mean $_{\text {all }}$ & 0.55 & 6.0 & 47.9 & 7.4 \\
\hline & & mean $_{\text {dayime }}$ & 0.50 & 8.0 & 48.6 & 9.4 \\
\hline & & mean $_{\text {nightime }}$ & 0.63 & 3.7 & 47.9 & 2.9 \\
\hline & & range & $<0.1^{\mathrm{a})} \sim 1.2$ & $<0.1^{\text {a) }} \sim 47.5$ & $15.5 \sim 128$ & $<1.0^{\mathrm{a})} \sim 35.8$ \\
\hline & \multirow{4}{*}{ Jan. 2002} & mean $_{\text {all }}$ & 0.58 & 0.8 & 7.5 & 2.6 \\
\hline & & mean $_{\text {daytime }}$ & 0.57 & 1.5 & 8.0 & 2.9 \\
\hline & & mean $_{\text {nightime }}$ & 0.59 & 0.2 & 7.1 & 2.4 \\
\hline & & range & $<0.1^{\mathrm{a})} \sim 0.82$ & $<0.1^{\text {a) }} \sim 3.1$ & $2.8 \sim 15.0$ & $<1.0^{\mathrm{a})} \sim 4.3$ \\
\hline \multirow{4}{*}{ IZO } & \multirow{4}{*}{ Dec. 2003} & mean $_{\text {all }}$ & 0.30 & 41.2 & 68.6 & 11.3 \\
\hline & & mean $_{\text {daytime }}$ & 0.32 & 63.4 & 95.9 & 9.5 \\
\hline & & mean $_{\text {nightime }}$ & 0.27 & 19.3 & 41.7 & 13.2 \\
\hline & & range & $<0.1^{\mathrm{a})} \sim 1.86$ & $<0.1^{\mathrm{a})} \sim>200^{\mathrm{b})}$ & $9.3 \sim>200^{\mathrm{b})}$ & $<1.0^{\mathrm{a})} \sim 38.1$ \\
\hline
\end{tabular}

IZO : Izumiotsu, OPU : Osaka Pref. Univ., a) not measured (below quanification limit); b) not measured (above quanification limit)

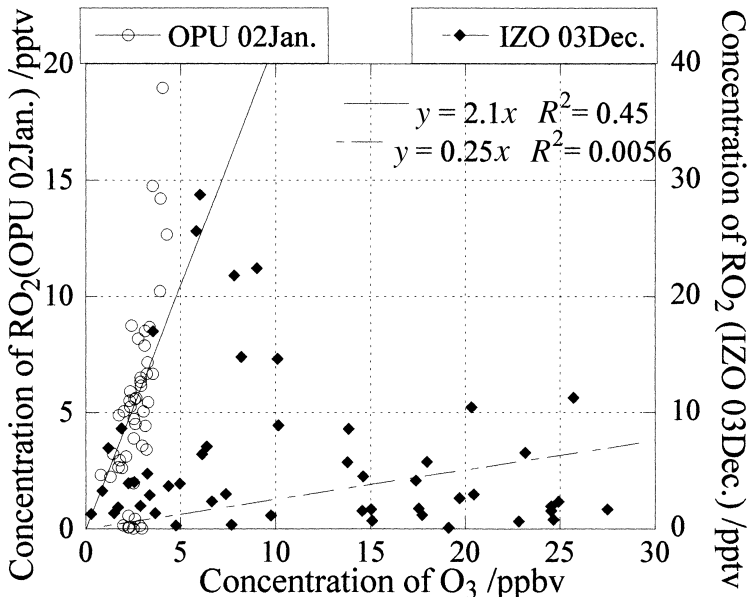

Fig. 4 Scatter plotts between concentration of $\mathrm{O}_{3}$ and concentration of $\mathrm{RO}_{2}$ at Izumiotsu and OPU

少し，日没後は大きな変動は見られなくなっている点であ る。これは太陽光によるオゾンの光分解により生じた $\mathrm{OH}$ ラジカル濃度の上昇によりもたらされる $\mathrm{RO}_{\mathrm{x}}$ ラジカル濃 度の上昇によるものと考えられる ${ }^{18)}$.またいずれの観測に おいても最大の $\mathrm{RO}_{2}$ 濃度は, 夜間の濃度レベルに対して いずれも 12〜16 pptv 高くなっていた. 今回 $2 つ の$ 観測場 所での 3 度の観測に押ける $\mathrm{RO}_{2}$ の日変動は, 過去に報告 されている清浄大気中での観測における結果と同様の日変 動を示し, 日中では太陽光強度に酷似した変動が見られ, 夜間では低濃度で存在し，大きな変動が見られなかっ た ${ }^{19) \sim 21)}$.

一方，両サイトにおける観測結果の相違点としては，大 阪府立大学の夜間における $\mathrm{RO}_{2}$ 濃度が $5 \sim 10 \mathrm{pptv}$ となっ ていることが確認されたのに対し，泉大津市，すなわち自 動車排ガスの影響を直接受ける大気の夜間における $\mathrm{RO}_{2}$ 濃度の多くは検出限界（3.5 pptv）以下であった。夜間に
存在する $\mathrm{RO}_{2}$ は，報告されているオゾンーオレフィン反 応 ${ }^{22) ~ 27)} \mathrm{NO}_{3}$-オレフィン反応 ${ }^{2829)}$ がラジカル生成に寄 与している結果と考えられる.

この点について，それぞれの観測における $\mathrm{CO}, \mathrm{NO}$, $\mathrm{NO}_{\mathrm{x}}\left(=\mathrm{NO}+\mathrm{NO}_{2}\right)$ 及び $\mathrm{O}_{3}$ それぞれの濃度の平均值, 最大・最小值，昼間・夜間平均值（Table 1）から検討を 行った.

特記すべき第一の点として, 大阪府立大学の 1 月と 9 月における昼間の $\mathrm{RO}_{2}$ 濃度の差異が小さいのに比べて, 両者の昼間の $\mathrm{O}_{3}$ 濃度の差は非常に大きくなっている点が 挙げられる. 昼間の $\mathrm{RO}_{2}$ の主生成反応として $\mathrm{O}_{3}$ の光分解 から生じた $\mathrm{OH}$ ラジカルからの生成が考えられおり, $\mathrm{RO}_{2}$ の生成速度は $\mathrm{OH}$ ，すなわち $\mathrm{O}_{3}$ に一次であると考えられ るが，ここではその効果が見られなかった．2番目として， 大阪府立大学では夜間のオゾン濃度が $2 \mathrm{ppbv}$ 程度しか存

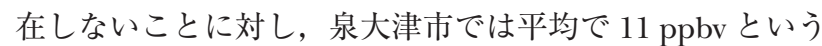
結果が得られている。夜間のラジカル生成反応と考えられ ている $\mathrm{O}_{3}-, \mathrm{NO}_{3}$ ラジカルーオレフィン反応においても 上記の昼間の $\mathrm{RO}_{2}$ 生成と同様に $\mathrm{O}_{3}$ 濃度に一次の反応であ る。これに関して，横軸をオゾン濃度とし，左縦軸を 2002 年 1 月の大阪府立大学に打ける, 右縦軸に泉大津に おける $\mathrm{RO}_{2}$ ラジカル濃度をそれぞれとった相関図を Fig. 4 に示す．先に述べたように大阪府立大学の 1 月では，才 ゾン濃度に対して $\mathrm{RO}_{2}$ ラジカル濃度は一次の相関が見ら れるが $\left(\mathbf{R}^{2}=0.45\right)$ ，これに対し泉大津では相関が見られ ない $\left(\mathrm{R}^{2}=0.0056\right)$.今回の観測結果では上述のように一 般的に考えられている $\mathrm{O}_{3}$ と $\mathrm{RO}_{2}$ ラジカル濃度との関係が 見られなかった．泉大津市に打いては夜間に $\mathrm{O}_{3}$ 濃度の上 昇が見られ，このことに関しても従来の大気化学反応系の 知見のみでは十分な説明ができない.

Table 1 にまとめた今回の観測結果からも分かるよう に, 自動車排ガスが多く, $\mathrm{NO}_{\mathrm{x}}$ 濃度が $100 \mathrm{ppbv}$ も存在す 


\section{るような都市污染大気中においてもラジカルの存在が確認 されたが，その濃度と清浄大気の濃度との間には大きな差 は見られなかった。今回の観測結果のみでは十分な説明を することができなかった，都市污染大気中における $\mathrm{O}_{3}$ と $\mathrm{RO}_{2}$ 濃度の関係については, 長期的な観測を行うととも に, 大気光化学反応にかかわる他の因子, 例えば非メタン 炭化水素類の分布や大気中エアロゾル濃度, 気象（風向な ど）についての観測，検討が必要である.}

\section{文献}

1) W. Chameides, D. D. Davis: J. Geophys. Res., 87, 4863 (1982).

2) M. Monica, D. Perner, E. M. Hackenthal, S. Klüzer, L. Schütz: J. Geophys. Res., 105, 22685 (2000).

3) C. A. Cantrell, D. H. Stedman: Geophys. Res. Lett., 9, 846 (1982).

4) C. A. Cantrell, D. H. Stedman, G. J. Wendel: Anal. Chem., 56, 1496 (1984).

5) C. A. Cantrell, R. E. Shetter, J. G. Calvert: Anal. Chem., 68, 4194 (1996).

6) C. Anastasi, R. V. Gladstone, M. G. Sanderson : Environ. Sci. Technol., 27, 474 (1993).

7) D. R. Hastie, M. Weissenmayer, J. P. Burrows, G. W. Harris: Anal. Chem., 68, 2048 (1996).

8) J. Hu, D. H. Stedman: Anal. Chem., 66, 3384 (1994).

9) E. L. Baardsen, R. W. Terhune: Appl. Phys. Lett., 21, 209 (1972).

10) C. C. Wang, L. I. Davis Jr., : Phys. Rev. Lett., 32, 349 (1974).

11) D. J. Creasey, P. A. Halfold-Maw, D. E. Heard, M. J. Pilling, B. J. Whittaker: J. Chem. Soc. Faraday Trans., 93, 2907 (1997).

12) T. M. Hard, R. J. O'Brien, C. Y. Chan, A. A.
Mehrabzadeh: Environ. Sci. Technol., 18, 768 (1984).

13) G. H. Mount: J. Geophys. Res., 97, 2427 (1992).

14) G. H. Mount, J. W. Harder: J. Atmos. Sci., 52, 3342 (1995).

15) Y. Kanaya, Y. Sadanaga, J. Hirokawa, Y. Kajii, H. Akimoto: J. Atmos. Chem., 38, 73 (2001).

16) C. M. Mihele, D. R. Hastie: Geophys. Res. Lett., 25, 1911 (1998).

17) Y. Maeda, K. Aoki, M. Munemori: Anal. Chem., 52, 307 (1980).

18) H. Levy II. : Science, 173, 141 (1971).

19) Y. Kanaya, K. Nakamura, S. Kato, J. Matsumoto, H. Tanimoto, H. Akimonoto: Atmos. Environ., 36, 4929 (2002).

20) X. Ren, G. D. Edwards, C. A. Cantrell, R. L. Lesher, A. R. Metcalf, T. Shirley, W. H. Brune: J. Geophys. Res., D19, 4605 (2003).

21) G. Salisbury, P. S. Monks, S. Bauguitte, B. J. Bandy, S. A. Penkett: J. Atmos. Chem., 41, 163 (2002).

22) R. Atkinson, S. M. Aschmann: Environ. Sci. Technol., 27, 1357 (1993).

23) S. Hatakeyama, H. Akimoto: Res. Chem. Intermed., 20, 503 (1994).

24) C. Schäfer, O. Horie, J. N. Crowley, G. K. Moortgat: Geophys. Res. Lett., 24, 1611 (1997).

25) S. E. Paulson, A. D. Sen, P. Liu, J. D. Fenske, M. J. Fox: Geophys. Res. Lett., 24, 3193 (1997).

26) N. M. Donahue, J. H. Kroll, J. G. Anderson, K. L. Demerjian: Geophys. Res. Lett., 25, 1611 (1998).

27) R. Atkinson, J. Arey: Atmos. Environ., 37, S197 (2003).

28) S. M. Japer, H. Niki : J. Phys. Chem., 16, 1629 (1975).

29) C. A. Cantrell, W. R. Stockwell, L. G. Anderson, K. L. Busarow, D. Perner, A. Schmeltekopf, J. G. Calvert, H. S. Johnston: J. Phys. Chem., 89, 139 (1985).

\section{要 旨}

2001 年 9 月と 2002 年 1 月及び 2003 年 12 月に化学増幅（PERCA）法を用いて都市污染大気中の過酸化 ラジカル $\left(\mathrm{RO}_{2}\right)$ の測定を行った。 2003 年の観測サイトは自動車から排ガスの影響を受けやすいサイトで あり，観測期間中の $\mathrm{NO}_{\mathrm{x}}$ 濃度は平均で $90 \mathrm{ppbv}$ を超えていた。 そのときの日中の $\mathrm{RO}_{2}$ 濃度は他の 2 回, 又 はこれまでに報告されているものと同程度であった。しかしながら，そのサイトにおける夜間の $\mathrm{RO}_{2}$ 濃度 の多くは検出限界 (3.5 pptv) 未満で他の観測とは異なっていた。また，2001 年と 2002 年の観測における $\mathrm{RO}_{2}$ 濃度に大きな差は見られなかったが，期間中の平均 $\mathrm{O}_{3}$ 濃度は大きく異なっていた. 今回の観測で得ら れた都市污染大気中の $\mathrm{RO}_{2}$ と $\mathrm{O}_{3}$ の関係については従来の大気化学の知見では十分に説明されず，高濃度污 染大気中のラジカル生成・消滅に関する知見が不十分であることが分かった。 